\title{
A comparison of physical activity levels in childcare contexts among Finnish and Dutch three-year-olds
}

Citation for published version (APA):

Soini, A., Gubbels, J., Saakslahti, A., Villberg, J., Kremers, S., Van Kann, D., Mehtala, A., De Vries, N., \& Poskiparta, M. (2016). A comparison of physical activity levels in childcare contexts among Finnish and Dutch three-year-olds. European Early Childhood Education Research Journal, 24(5), 775-786. https://doi.org/10.1080/1350293X.2016.1213569

Document status and date:

Published: 01/10/2016

DOI:

10.1080/1350293X.2016.1213569

Document Version:

Publisher's PDF, also known as Version of record

Document license:

Taverne

Please check the document version of this publication:

- A submitted manuscript is the version of the article upon submission and before peer-review. There can be important differences between the submitted version and the official published version of record.

People interested in the research are advised to contact the author for the final version of the publication, or visit the DOI to the publisher's website.

- The final author version and the galley proof are versions of the publication after peer review.

- The final published version features the final layout of the paper including the volume, issue and page numbers.

Link to publication

\footnotetext{
General rights rights.

- You may freely distribute the URL identifying the publication in the public portal. please follow below link for the End User Agreement:

www.umlib.nl/taverne-license

Take down policy

If you believe that this document breaches copyright please contact us at:

repository@maastrichtuniversity.nl

providing details and we will investigate your claim.
}

Copyright and moral rights for the publications made accessible in the public portal are retained by the authors and/or other copyright owners and it is a condition of accessing publications that users recognise and abide by the legal requirements associated with these

- Users may download and print one copy of any publication from the public portal for the purpose of private study or research.

- You may not further distribute the material or use it for any profit-making activity or commercial gain

If the publication is distributed under the terms of Article $25 \mathrm{fa}$ of the Dutch Copyright Act, indicated by the "Taverne" license above, 


\section{A comparison of physical activity levels in childcare contexts among Finnish and Dutch three-year-olds}

Anne Soini, Jessica Gubbels, Arja Sääkslahti, Jari Villberg, Stef Kremers, Dave Van Kann, Anette Mehtälä, Nanne De Vries \& Marita Poskiparta

To cite this article: Anne Soini, Jessica Gubbels, Arja Sääkslahti, Jari Villberg, Stef Kremers, Dave Van Kann, Anette Mehtälä, Nanne De Vries \& Marita Poskiparta (2016) A comparison of physical activity levels in childcare contexts among Finnish and Dutch three-year-olds, European Early Childhood Education Research Journal, 24:5, 775-786, DOI: 10.1080/1350293X.2016.1213569

To link to this article: https://doi.org/10.1080/1350293X.2016.1213569

Published online: 02 Sep 2016.

Submit your article to this journal

Lll Article views: 342

Q View related articles $\sqsubset$

View Crossmark data [ᄌ

Citing articles: 3 View citing articles 


\title{
A comparison of physical activity levels in childcare contexts among Finnish and Dutch three-year-olds
}

\author{
Anne Soini $^{\text {a* }}$, Jessica Gubbels ${ }^{\mathrm{b}}$, Arja Sääkslahti ${ }^{\mathrm{c}}$, Jari Villberg ${ }^{\mathrm{d}}$, Stef Kremers ${ }^{\mathrm{b}}$, \\ Dave Van Kann ${ }^{\mathrm{b}}$, Anette Mehtälä ${ }^{\mathrm{d}}$, Nanne De Vries ${ }^{\mathrm{b}}$ and Marita Poskiparta ${ }^{\mathrm{d}}$ \\ ${ }^{a}$ Department of Education/Early Childhood Education, University of Jyväskylä, Finland; \\ ${ }^{b}$ Department of Health Promotion, Maastricht University, The Netherlands; ${ }^{c}$ Department \\ of Sport Sciences, University of Jyväskylä, Finland; ${ }^{d}$ Department of Health Sciences, \\ University of Jyväskylä, Finland
}

The aim of the current study was to determine Finnish and Dutch three-year-old preschool children's physical activity (PA) levels and how levels vary across gender, location, time of day and social contexts in both countries. A modified version of the Observational System for Recording Physical Activity in Children-Preschool (OSRAC-P) was used to measure children's PA levels and contextual variables (e.g. group composition, prompts) of children attending childcare centres in Finland and the Netherlands. In total, 90 Finnish children (46 boys and 44 girls) and 97 Dutch children (46 boys and 51 girls) were observed. Three-level linear regression analyses with cross level interactions were used to assess differences between the countries in the association between the context variables and PA. During the observations, the present sample of children was mostly sedentary in nature. Outdoor location and prompts (both positive and negative) were associated with higher levels of activity in both countries. Non-solitary playing was associated with higher activity levels in the Netherlands, but not in Finland, whereas child-initiated play was positively associated with Finnish but not Dutch children's PA levels. Finnish children were more active in the morning compared to the afternoon, while in the Dutch children PA was unaffected by time. The present findings indicate that better understanding of the contextual factors and interactions in children's PA behaviours across the two countries could help in planning childcare interventions to increase the PA levels of preschool children.

Keywords: physical activity (PA); direct observation; childcare centre; country comparison; preschool children

\section{Introduction}

Nearly $70 \%$ of three-year-old children in Europe attend childcare or early education services, whereas in other continents the numbers are much lower (OECD 2014). There is some evidence that childcare centres influence children's physical activity (PA) levels (Finn, Johannsen, and Specker 2002; Pate et al. 2004; Strong et al. 2005; Pate et al. 2008). Finn et al. (2002) concluded that among children attending childcare, the childcare centre was the strongest predictor of activity levels, with more than $50 \%$ of the daily PA performed during childcare hours. However, various studies have indicated

\footnotetext{
*Corresponding author. Email: anne.soini@jyu.fi
} 
that PA levels are generally very low among preschool children during their time in childcare settings (Oliver, Schofield, and Kolt 2007; Pate et al. 2008; Brown et al. 2009b; Reilly 2010; Gubbels et al. 2011). A US study by Brown et al. (2009b) reported $94 \%$ of the indoor activities observed to be sedentary. A smaller but nevertheless substantial proportion (59\%) of the indoor activities observed among Dutch children also classified as sedentary (Gubbels et al. 2011), indicating that sedentariness might be more pronounced in US preschoolers.

In a light of the socio-ecological framework, Hinkley et al. (2008) reviewed correlates of preschool children's PA level and showed that children's demographic and biological characteristics, as well as their physical and social environments are significantly associated with a children's total PA. Various studies have found links between physical environment factors in the childcare setting (e.g. the ground surface, playground markings, open space, play equipment) and children's PA (Zask et al. 2001; Dowda et al. 2004; Boldemann et al. 2006; Ridgers et al. 2007; Bower et al. 2008; Cardon et al. 2008; Hannon and Brown 2008; Cosco et al. 2010; Gubbels, Van Kann, and Jansen 2012). Furthermore, boys have been found to be more active than girls (Oliver et al. 2007; Hinkley et al. 2008; Pate et al. 2008), children are more active outdoors (Finn et al. 2002; Pate et al. 2004; Boldeman et al. 2006; Hinkley et al. 2008), and children's PA increases in warm seasons and decreases in the colder seasons (Carson and Spence 2010).

Social environment factors, such as positive prompts by staff members (Brown et al. 2009a) and peers (Gubbels et al. 2011), have been shown to be associated with children's increased PA intensity. Despite these positive associations, teachers and peers rarely prompt children to increase their PA. Moreover, teacher-initiated play was negatively associated with children's levels of PA (Brown et al. 2009b). European studies have also indicated negative relationships between the presence of more childcare staff and peers (Cardon et al. 2008) or direct involvement of staff and peers in children's play (Gubbels et al. 2011), and children's activity levels.

Currently, there is a lack of observational studies on preschool children in Europe. Such observational studies provide valuable information on the context of PA behaviours, which cannot be derived from studies using accelerometer or other objective measurements of PA. Such contextual information can inform preventive interventions promoting PA in childcare, and have implications for both practitioners and researchers. The childcare setting holds great potential to make an important contribution to the welfare and health of young children by promoting PA (Pate et al. 2004; Bower et al. 2008; Hinkley et al. 2008; Pate et al. 2008; Ward 2010). Furthermore, positive patterns of engagement in PA demonstrated during childhood are critical for the maintenance of a physically active lifestyle during both adolescence and adulthood (Strong et al. 2005).

In Finland, Recommendations for Physical Activity in Early Childhood Education (2005) are a part of the National Guidelines on Early Childhood Education Curriculum (ECEC). The recommendations concern the amount of PA (two hours of daily brisk PA), its quality, settings, and suitable equipment for implementing it. Further, childcare centres should take part in sport campaigns and support staff knowledge on the importance of PA, additionally, childcare staff should plan and arrange purposeful and varied physical education (PE) (Recommendations for Physical Activity in Early Childhood Education, 2005). It is noteworthy that, in the Netherlands, no national guidelines exist for Dutch children up to age four.

The aim of this descriptive study was to determine existing PA levels among threeyear-old children attending childcare in Finland and the Netherlands, and how these 
vary by gender, primary location (i.e. indoor vs outdoor), time of day (i.e. morning vs afternoon), social context (i.e. group composition, initiator of activity, prompts), outdoor temperatures and weather conditions.

\section{Methods}

\section{Participants and sampling}

In Finland, recruitment was performed in the city of Jyväskylä. A total of 14 childcare centres volunteered their participation in the study. In Finland, three-year-olds in childcare are most commonly mixed in a group with four- and five-year-olds, while one- and two-year-olds are often grouped together. Finnish childcare centres in the present study provided care for an average of 74 children $(S D=20)$ in 4 groups $(S D=1)$. The mean number of staff members per centre was $16(S D=5)$. All the families of the three-yearold children attending the childcare centres $(N=179)$ were invited to participate. One hundred and two (57\%) parents provided informed consents. The children's PA data were collected between August and October 2010. Six children were not present and six children were attending for only half a day during the observations, and were therefore excluded from the final sample of 90 children (46 boys and 44 girls) observed in Finland.

In the Netherlands a large Dutch childcare organization was approached to participate in the study, and gave consent to conduct the study. All nine childcare centres in Maastricht run by this organization were approached and agreed to participate. In the Netherlands, childcare centres offer care for babies as young as six weeks to children up to four years, three-year-olds are often grouped with two-year-olds. In the present study, the Dutch childcare centres provided care for an average of 92 children $(S D=$ $28)$ in five groups $(S D=1)$. The mean number of staff members per centre was 20 $(S D=6)$. All the parents of the three-year-old children attending these childcare centres were informed about the study, and none of them refused to participate. Children's PA was observed in May and June 2008. A total of 97 three-year-olds (46 boys and 51 girls) were observed in the Netherlands.

The typical daily timetables in the Finnish and Dutch childcare centres are described in Table 1. The ethics committee of the University of Jyväskylä, and the Social Affairs and Health officer of the city of Jyväskylä approved the study. The Dutch study complied with the Dutch 'Medical Research Involving Humans Act'.

\section{Measures and procedures}

A translated and modified version of the Observational System for Recording Physical Activity in Children-Preschool Version (OSRAC-P; Brown et al. 2006) was used to measure children's PA intensity, location, contexts, prompts and interactions. The design of the Finnish study was based on the Dutch study by Gubbels et al. (2011), with some minor adjustments to adapt to the Finnish situation. Two researchers in each country observed PA and contextual factors using a procedure in which an observation period of 15 seconds was followed by 30 seconds for recording the observation. This procedure was repeated eight times for a total of six minutes per child. In Finland, each child was observed twice a day, both in the morning (between 8 a.m. and 12 noon) and afternoon ( 2 p.m. and 5 p.m.), yielding a total of 16 observations per child. In the Netherlands, each child was observed either in the morning or afternoon, yielding a 
Table 1. Typical daily programmes in Finnish and Dutch childcare centres.

\begin{tabular}{|c|c|c|c|}
\hline \multicolumn{2}{|l|}{ Finland } & \multicolumn{2}{|r|}{ The Netherlands } \\
\hline Time & Content of activity & Time & Content of activity \\
\hline $6.30-8.00$ & $\begin{array}{l}\text { Centre opens, unstructured } \\
\text { play indoors }\end{array}$ & $7.30-9.30$ & $\begin{array}{l}\text { Centre opens, unstructured } \\
\text { play indoors }\end{array}$ \\
\hline $8.00-9.00$ & Breakfast & $9.30-10.00$ & Snack \\
\hline $9.00-11.00$ & $\begin{array}{l}\text { Structured activities inside, } \\
\text { unstructured play indoors } \\
\text { and/or outdoors }\end{array}$ & $10.00-11.30$ & $\begin{array}{l}\text { Structured activities inside, } \\
\text { unstructured play indoors } \\
\text { and/or outdoors }\end{array}$ \\
\hline $11.00-12.00$ & Lunch & $11.30-12.30$ & Lunch \\
\hline $12.00-14.00$ & Resting time & $12.30-15.00$ & $\begin{array}{l}\text { Resting time (younger } \\
\text { children)/unstructured play } \\
\text { indoors (older children) }\end{array}$ \\
\hline 14.00 & Snack & 15.0 & Snack \\
\hline $14.30-15.00$ & Unstructured play indoors & $15.30-18.00$ & $\begin{array}{l}\text { Unstructured play indoors and/ } \\
\text { or outdoors }\end{array}$ \\
\hline $15.00-17.00$ & Unstructured pla & & \\
\hline 17.00 & Centre closes & 18.00 & Centre closes \\
\hline
\end{tabular}

total of eight observations per child. The total number of single observations for both countries combined was thus 2216 (1440 in Finland; 776 in the Netherlands). In both countries, children were randomly selected for observation and they were not observed during meals or rest times. To ensure accuracy of data, observer training (e.g. initial observer orientation, study of the observation manual and the memorization of codes and categories, direct in situ training session in field settings) is recommended (Brown et al. 2009c). Therefore, in both countries, before the data collection all field researchers were trained with the method by studying the instruments and background information, and subsequently observing children via videotape and 'live' in the childcare settings.

Cohen's kappa was used to determine the inter-rater reliability (IRR) of the two observers for the observations of the OSRAC-P variables (i.e. activity intensity, type of activity, group composition, indoor and outdoor contexts, initiator of activity, prompts) in both countries. Furthermore, to assess cross-country inter-observer agreement, a separate sample of children not included in the final study, was independently observed via videotape by one of the two researchers of each country. This resulted in cross-country coding of 305 observation intervals, i.e. $13.8 \%$ of the observation intervals in the main study (2216 intervals), sufficing the OSRAC-P norm of at least $12 \%$ independent coding (Brown et al. 2009c).

PA intensity levels were measured on a 5 -point scale $(1=$ stationary or motionless, $2=$ stationary with limb or trunk movements, $3=$ slow or easy movements, $4=$ moderate movements, 5 = fast movements) and reflected the highest intensity level reached by the child during each 15-second observation period. For the purpose of this study and further comparison, activity levels $\leq 2$ were regarded as sedentary behaviour, activity level 3 as light PA and levels $4-5$ as moderate-to-vigorous physical activity (MVPA) (Bower et al. 2008; Brown et al. 2009b; Gubbels et al. 2011).

OSRAC-P scales assessing contextual variables primary location (inside vs outdoor) and time of day (morning vs afternoon) were used (Brown et al. 2006). In addition, the following social OSRAC-P scales were assessed: group composition (i.e. solitary, one-to-one adult [engaging in an activity with or in proximity to only 
an adult or being in an activity area with only an adult], one-to-one peer [engaging in an activity with or in proximity to a peer or being in an activity area with a peer], group of children [engaging in an activity with or in proximity to peers without an adult or in an activity area with peers without an adult] group of children with adult/adults [engaging in an activity with or in proximity to peers and an adult or in an activity area with them]), initiator of activity (child or adult) and prompts (no prompts, staff member's/ peers' positive prompts to increase PA or negative prompts to decrease PA). Children's gender was also recorded. Finally, weather conditions and outdoor temperatures were recorded per observation day.

\section{Statistical analyses}

The scores of both observers on dichotomous variables (e.g. prompt by staff, yes/no) were combined by coding the variable as present (1) when one or both observers rated that variable as present, and coding it as absent (0) when both rated it as absent. For the continuous variables (e.g. activity intensity), the mean of the scores of both observers was calculated.

The mean IRR of the variables assessed was $0.6(S D=0.2 ; p<.001)$ in Finland, and $0.7(S D=0.2 ; p<.001)$ in the Netherlands. The intraclass correlation used to determine cross-country IRR of two observers for the activity intensity variable was $0.7(p<.001)$.

Differences in the contextual variables, social context and gender between Finnish and Dutch children were examined using chi-square tests. Differences in mean activity intensity between the Finnish and Dutch children were examined using independent sample $t$-tests.

The association between gender (boy vs girl), primary location (outdoor vs indoor), time of day (afternoon vs morning), group composition (non-solitary vs solitary), initiator of activity (child vs adult), prompts (no prompt vs positive or negative prompt), temperature (linear) and weather condition (rain vs sunny, with a clear sky or cloudy and dry) as independent, and mean PA intensity levels as dependent variables was examined using three-level linear regression, with cross-level interaction (with measurement level, child level, centre level) to examine differences between countries in these associations. All analyses were performed using SPSS 18.0 and STATA 12. In all analyses, $P$-values $<.05$ were considered statistically significant.

\section{Results}

\section{Temperature and weather conditions}

The mean outdoor temperature was $12.5^{\circ} \mathrm{C}$ during the Finnish observations (range: $2^{\circ}$ $\mathrm{C}-20^{\circ} \mathrm{C}$ ) and $20.5^{\circ} \mathrm{C}$ during Dutch observations (range: $14^{\circ} \mathrm{C}-26^{\circ} \mathrm{C}$ ). This difference was significant $(p<.001)$. Most of the time the weather was cloudy and dry $(53 \%)$ or sunny with a clear sky $(33 \%)$; the least prevalent was rain $(14 \%)$. Differences between the countries in temperature categories and weather conditions, and in sedentary and MVPA associated with these categories are described in Table 2.

\section{Contextual variables and activity levels}

According to Chi-Square tests, children's indoor PA levels were mostly sedentary in nature: $79 \%$ of total intervals recorded as sedentary, and only 3\% coded as MVPA. 
Table 2. Differences between countries in percentages of observations observed and levels of sedentary activities and MVPA $(N=187)$.

\begin{tabular}{|c|c|c|c|c|c|c|c|c|c|}
\hline \multirow[b]{2}{*}{ Observed categories } & & $\begin{array}{l}\text { Finland } \\
(n=90)\end{array}$ & $\begin{array}{l}\text { The Netherlands } \\
\qquad(n=97)\end{array}$ & \multirow[b]{2}{*}{$p$-value* } & \multicolumn{2}{|c|}{$\frac{\text { Finland }(n=90)}{\text { Activity levels }(\%)}$} & \multicolumn{2}{|c|}{$\begin{array}{l}\text { The Netherlands } \\
(n=97) \\
\text { Activity levels }(\%)\end{array}$} & \multirow[b]{2}{*}{$p$-value $* *$} \\
\hline & & \multicolumn{2}{|c|}{ Prevalence (\%) } & & Sedentary & MVPA & Sedentary & MVPA & \\
\hline \multirow[t]{2}{*}{ Gender } & Boys & 51 & 47 & .098 & 71 & 7 & 58 & 6 & $<.001$ \\
\hline & Girls & 49 & 53 & & 75 & 4 & 54 & 11 & $<.001$ \\
\hline \multirow[t]{2}{*}{ Time of day } & Morning & 50 & 47 & .247 & 66 & 7 & 58 & 9 & .037 \\
\hline & Afternoon & 50 & 53 & & 79 & 4 & 54 & 9 & $<.001$ \\
\hline \multirow[t]{2}{*}{ Primary location } & Indoor & 54 & 53 & .452 & 84 & 3 & 70 & 4 & $<.001$ \\
\hline & Outdoor & 46 & 48 & & 59 & 8 & 41 & 14 & $<.001$ \\
\hline \multirow[t]{5}{*}{ Group composition } & Solitary & 30 & 23 & $<.001$ & 68 & 5 & 39 & 15 & $<.001$ \\
\hline & One-to-one adult & 7 & 5 & .049 & 71 & 2 & 53 & 8 & .069 \\
\hline & One-to-one peer & 17 & 17 & .896 & 69 & 7 & 47 & 10 & $<.001$ \\
\hline & Group adult & 26 & 26 & .884 & 83 & 4 & 72 & 3 & .001 \\
\hline & Group child & 21 & 30 & $<.001$ & 71 & 7 & 61 & 8 & .069 \\
\hline \multirow[t]{2}{*}{ Initiator of activity } & Adult & 31 & 17 & $<.001$ & 83 & 3 & 67 & 5 & $<.001$ \\
\hline & Child & 76 & 91 & $<.001$ & 70 & 6 & 55 & 9 & $<.001$ \\
\hline \multirow[t]{5}{*}{ Prompts } & No prompts & 84 & 74 & $<.001$ & 75 & 5 & 59 & 8 & $<.001$ \\
\hline & Staff positive & 13 & 7 & $<.001$ & 66 & 8 & 37 & 14 & .001 \\
\hline & Staff negative & 1 & 10 & $<.001$ & 83 & 0 & 73 & 5 & .630 \\
\hline & Peer positive & 3 & 5 & .001 & 59 & 5 & 26 & 29 & .002 \\
\hline & Peer negative & 1 & 5 & $<.001$ & 14 & 29 & 36 & 10 & .303 \\
\hline \multirow[t]{3}{*}{ Temperature } & $\leq 10^{\circ} \mathrm{C}$ & 23 & 0 & $<.001$ & 75 & 6 & - & - & - \\
\hline & $11-20^{\circ} \mathrm{C}$ & 77 & 52 & & 72 & 5 & 57 & 10 & $<.001$ \\
\hline & $21^{\circ} \mathrm{C} \geq$ & 0 & 49 & & - & - & 55 & 8 & - \\
\hline \multirow[t]{3}{*}{ Weather } & Sunny, with clear sky & 33 & 33 & .002 & 72 & 5 & 55 & 11 & $<.001$ \\
\hline & Cloudy and dry & 52 & 57 & & 70 & 7 & 54 & 9 & $<.001$ \\
\hline & Rain & 16 & 10 & & 83 & 3 & 74 & 5 & .216 \\
\hline
\end{tabular}

Note. Sedentary = Levels 1-2; Moderate-to-vigorous physical activity, MVPA = Levels 4-5; $M=$ mean; $S D=$ Standard Deviation. * $p$-values from Pearson Chi-Square Tests used to compare differences in background characteristics between countries.

**To compare percentages of levels of sedentary activities and MVPA between countries. 
Outdoors, 53\% PA observations were classified as sedentary behaviour, whereas $10 \%$ were classified as MVPA. The initiators of the activities were most frequently children $(81 \%)$. Staff and peers rarely prompted children to increase or decrease their PA: no prompts were recorded in $81 \%$ of all observations. Cross-country differences were more pronounced in the social and weather-related variables than in the non-social context variables. The Finnish children spent significantly more time in sedentarylevel activities and less time in MVPA compared to the Dutch children in most of the observed categories (see Table 2).

\section{Associations between observed contexts and $P A$}

The results of the multi-level linear regression are presented in Table 3. With respect to the primary location of the observations, children were significantly more active outdoors than indoors (activity intensity 2.65 vs 2.18 , respectively; $p<.001$ ). In the Netherlands, an outdoor location had a stronger positive influence on children's activity levels than in Finland $(p<.001)$, although the influence was significant in both countries. All prompts (both positive and negative) were associated with an increase in the children's PA level in both countries. Non-solitary play was associated with higher activity levels in the Netherlands, whereas in Finland child-initiated play was positively associated with the children's PA levels. Finally, the Finnish children were less active in the afternoon compared to the morning, while the Dutch children's PA levels were unaffected by time of day.

\section{Discussion}

The present study applied direct observation to compare Finnish and Dutch three-yearold children's PA behaviour during childcare. In line with previous findings (Oliver et al. 2007; Pate et al. 2008; Brown et al. 2009b; Gubbels et al. 2011), the present sample of children engaged in sedentary activities in $79 \%$ of indoor and $53 \%$ of outdoor observations. The results further showed significant differences between the countries in children's PA levels: the Finnish children spent significantly more time in sedentary-level activities and less time in MVPA compared to the Dutch children.

Several contextual variables had a differential influence on PA depending on the country. Surprisingly, this mainly concerned non-social influences: time of day and location, in addition to group composition. The significant interaction between country and time of day showed that the Finnish children were less active in the afternoon compared to mornings, while the Dutch children's PA levels were unaffected by time of day. The activities planned during an average childcare day provide little explanation for this difference, as they were very similar in both countries. The only difference worth noting is that in Finland fixed time for indoor and outdoor playing was scheduled, while in the Netherlands afternoons were spent flexibly, playing either indoors or outdoors, depending on, for instance, the weather and opportunities that arose during the day.

In the present study, temperature and weather conditions varied significantly between the two countries. However, we found no significant association between the temperature or weather variables and children's PA behaviour, and the absence of significant interactions between country and these variables indicates that these variables did not explain the differences in PA levels between the two countries. In line with this, Finn et al. (2002) found no seasonal variations in children's PA levels. Baranowski 
Table 3. Children's mean PA intensity levels in Finland and in the Netherlands: three level linear regression.

\begin{tabular}{|c|c|c|c|c|c|c|c|}
\hline \multirow[b]{2}{*}{ Observed categories } & \multicolumn{3}{|c|}{ Finland $(\mathrm{n}=90)$} & \multicolumn{3}{|c|}{ The Netherlands $(\mathrm{n}=97)$} & \multirow[b]{2}{*}{$\begin{array}{c}p- \\
\text { value* }\end{array}$} \\
\hline & Regression coefficient & $\begin{array}{c}p- \\
\text { value }\end{array}$ & $95 \%$ confidence interval & Regression coefficient & $\begin{array}{c}p- \\
\text { value }\end{array}$ & $95 \%$ confidence interval & \\
\hline$\overline{\text { Girl }}$ & $-.10(.07)$ & .177 & $-.24 \pm .04$ & $.05(.09)$ & .541 & $-.12 \pm .22$ & .232 \\
\hline Outdoor & $.39(.05)$ & $<.001$ & $.29 \pm .48$ & $.72(.06)$ & $<.001$ & $.61 \pm .83$ & $<.001$ \\
\hline Afternoon & $-.09(.04)$ & .024 & $-.17 \pm-.12$ & $.10(.10)$ & .329 & $-.10 \pm .31$ & .024 \\
\hline Non-solitary & $.06(.04)$ & .145 & $.02 \pm .15$ & $.29(.06)$ & $<.001$ & $.17 \pm .40$ & .001 \\
\hline Child-initiated & $.15(.06)$ & .013 & $.03 \pm .27$ & $.09(.09)$ & .305 & $-.08 \pm .27$ & .196 \\
\hline No prompts & $-.25(.06)$ & $<.001$ & $-.36 \pm-.14$ & $-.18(.06)$ & .001 & $-.29 \pm-.07$ & .087 \\
\hline Temperature & $-.01(.01)$ & .077 & $-.03 \pm .00$ & $.01(.02)$ & .692 & $-.03 \pm .05$ & .062 \\
\hline Rain & $-.03(.06)$ & .645 & $-.14 \pm .09$ & $.34(.19)$ & .080 & $-.04 \pm .72$ & .760 \\
\hline
\end{tabular}

Note. Girl vs boy; outdoor vs indoor; afternoon vs morning; non-solitary vs solitary; child-initiated vs adult-initiated; no prompts vs positive or negative prompts; temperature (linear); rain vs sunny with clear sky or cloudy and dry; $p$-values* for differences between countries from cross-level interaction test. 
et al. (1993) indicated in their observational study that differences in children's PA were more related to time spent outdoors than to season or weather conditions. To date few seasonal studies have been conducted among preschool-aged children, and their findings have been conflicting (Carson and Spence 2010).

A Belgian study reported significant increases in children's objectively measured PA intensity during preschool recess and times of unstructured free plays that were taken as an opportunity to be physically active (Verbestel et al. 2011). Consistent with several previous findings (Pate et al. 2004; Boldeman et al. 2006; Hinkley et al. 2008; Brown et al. 2009b), the present sample of children in both countries was physically more active outdoors than indoors, although outdoor location had a stronger positive influence on PA in the Dutch than Finnish children. Finnish children have two structured recess sessions, in the Netherlands the childcare programmes are less strict, allowing children to play in the outdoor play area throughout the day. This may explain why the outdoor location had a stronger positive influence on PA in the Dutch than Finnish children. The Finnish children were observed for the most part in non-solitary play, however, their solitary play was associated with increased PA levels, as also noted in the US by Brown et al. (2009b). In contrast, non-solitary play was associated with higher activity levels among Dutch children in this study.

In general, children tend to be less active the more staff members there are present or involved with children's play (Cardon et al. 2008; Brown et al. 2009b; Gubbels et al. 2011). Also in the present study, children were more sedentary when staff members were involved in children's activities, or when the initiator of the play was an adult. Although PA promotion is part of the childcare curriculums in involved countries, it is a matter for concern that the majority of the observations did not include any oral prompting by staff or peers, despite the fact that all prompts were positively associated with time spent in MVPA. Similarly, other studies have confirmed that positive prompts by staff (Brown et al. 2009a) and peers (Gubbels et al. 2011) have positive associations with children's PA intensity. Childcare staff may assume that children are naturally very active and that they engage in sufficient activity, and therefore lay less emphasis on the importance for children of an active lifestyle (Pate et al. 2008). Indeed, childcare staff should not assume that, because children are playing outdoors, they are necessarily engaging in higher-level activities. Perhaps a more unstructured and flexible approach is beneficial for raising children's PA levels.

The differences between the two countries in children's PA levels were pronounced, although the differences in the social context, such as group sizes and numbers of children and staff members in the current childcare centres, were not. However, one notable difference between the countries was revealed in the children's typical childcare attendance. If children attend childcare once or twice per week, as is typical in the Netherlands (European Commission's Expert Group on Gender and Employment Issues [EGGE] 2009), this factor alone may positively influence their level of PA. For Finnish children, who often attend childcare five days a week (OECD 2014), childcare is part of their normal daily routine and may not exert any particular influence on their PA. Another explanation for the cross-country difference may be found in group membership: Finnish three-year-olds were grouped with four- to five-year-old children, whereas Dutch three-year-old children were often grouped with two-year-olds. The Finnish observers may have unintentionally underrated the three-year-olds' behaviour when this was observed against the backdrop of the older, more skilled children present, while in the Netherlands the opposite may have occurred: the observers may have overrated the PA of the Dutch three-year-olds by unwittingly comparing them with the two- 
year-olds. The sufficiently high cross-country IRR contradicts this explanation, though. A final explanation might lie in differences in the physical childcare environment (e.g. playground size, play equipment) in the two countries, which was not taken into account in the study. The physical environment has previously been shown to significantly influence the activity levels of children in childcare (e.g. Cosco et al. 2010; Gubbels et al. 2012).

A strength of this study is that PA levels were directly observed using the OSRAC-P method in two European countries. Observations were made in a total of 23 childcare centres indoors and outdoors, and during both mornings and afternoons, thereby covering regular childcare attendance times in both Finland and the Netherlands. The childcare daily schedules and outdoor times in both countries were very similar, and no major differences were observed in programmes. The benefit of the observation format was that it recorded not only the intensity of activity, but also where, how and in what kind of interaction the activity was being engaged. Moreover, the OSRAC-P has been shown to be a valid and reliable tool for measuring PA among preschool-aged children (Brown et al. 2006; Trost 2007; Pate, O’Neill, and Mitchell 2010).

This study has limitations that should be noted. This study was combined from two separate data collections (the Netherlands 2008 and Finland 2010), therefore some methodological differences existed. Further, the generalizability of the findings could be limited by the fact that in both countries all the participating childcare centres and children were located in the same city, though, the samples represented the general population structure. In Finland the number of observations was higher than in the Netherlands, however, comparisons were made between mean values, therefore it was possible to include all existing Finnish observations to provide more accurate data without affecting the final results. Results with regard to time of day could have been influenced by the fact that children were observed either during the morning or afternoon in the Netherlands, though. Furthermore, the direct observation method is based on subjective assessments. The fact that the observers in the two countries were not the same might have influenced the findings, possibly explaining the systematically higher PA levels found in the Dutch compared to Finnish children. For linguistic reasons, however, it would not have been possible to use the same researcher in each country. The inter-observer reliabilities in both countries, as well as cross-country indicated appropriate levels of agreement.

\section{Conclusion}

In light of the growing concern about children's PA behaviour, this study indicated that interventions at the childcare level are needed to increase the PA levels of both Finnish and Dutch three-year-old preschool children. The findings emphasized that the childcare setting itself may play an important part in promoting positive patterns of health behaviour during early childhood. Interventions should focus on increasing children's outdoor time, free play, positive prompting and encouragement by staff members. A better understanding of the interactions between and within different contextual factors in children's behaviours should help to identify ways of promoting participation in PA during childcare attendance.

The present sample of children engaged in sedentary activities in $79 \%$ of indoor and $53 \%$ of outdoor observations. Children were more sedentary when staff members were involved in children's activities, or when the initiator of the play was an adult. The majority of the observations did not include any oral prompting by staff or peers, 
despite the fact that positive prompts were positively associated with time spent in MVPA. The Finnish children spent significantly more time in sedentary-level activities and less time in MVPA compared to the Dutch children. The present findings indicate that better understanding of the contextual factors and interactions in children's PA behaviours across the two countries could help in planning childcare interventions to increase the PA levels of preschool children.

\section{Acknowledgements}

We appreciate the cooperation of the Finnish and Dutch childcare centres, children and their parents who participated in this study.

\section{Conflict of interest}

The authors state that they have no conflicts of interest.

\section{References}

Baranowski, T., W. O. Thompson, R. H. DuRant, J. Baranowski, and J. Puhl. 1993. "Observations on Physical Activity in Physical Locations: Age, Gender, Ethnicity, and Month Effects." Research Quarterly for Exercise and Sport 64: 127-133.

Boldeman, C., M. Blennow, H. Dal, F. Mårtensson, A. Raustorp, K. Yuen, and U. Wester. 2006. "Impact of Preschool Environment upon Children's Physical Activity and sun Exposure." Preventive Medicine 42: 301-308.

Bower, J. K., D. P. Hales, D. F. Tate, D. A. Rubin, S. E. Benjamin, and D. S. Ward. 2008. "The Childcare Environment and Children's Physical Activity." American Journal of Preventive Medicine 34: 23-29.

Brown, W. H., H. S. Googe, K. L. McIver, and M. J. Rathel. 2009a. "Effects of Teacher-encouraged Physical Activity on Preschool Playgrounds." Journal of Early Intervention 31: 126145.

Brown, W. H., K. A. Pfeiffer, K. L. McIver, M. Dowda, C. L. Addy, and R. R. Pate. 2009 b. "Social and Environmental Factors Associated with Preschoolers' Nonsedentary Physical Activity." Child Development 80: 45-58.

Brown, W. H., K. A. Pfeiffer, K. L. McIver, M. Dowda, M. J. C. A. Almeida, and R. R. Pate. 2006. “Assessing Preschool Children's Physical Activity: The Observational System for Recording Physical Activity in Children-preschool Version." Research Quarterly for Exercise and Sport 77: 167-176.

Brown, W. H., K. A. Pfeiffer, K. L. McIver, M. Dowda, M. J. Almeida, and R. R. Pate. 2009c. "Observational System for Recording Physical Activity in Children-Preschool (OSRACP)." OSRAC-P Training Manual for Observers Columbia: University of South Carolina.

Cardon, G., E. Cauwenberghe, V. Labarque, L. Haerens, and I. De Bourdeaudhuij. 2008. "The Contribution of Preschool Playground Factors in Explaining Children's Physical Activity During Recess." International Journal of Behavioral Nutrition and Physical Activity 5: 11. doi:10.1186/1479-5868-5-11.

Carson, V., and J. C. Spence. 2010. "Seasonal Variation in Physical Activity among Children and Adolescents: A Review." Pediatric Exercise Science 22: 81-92.

Cosco, N. G., R. C. Moore, and M. Z. Islam. 2010. "Behavior Mapping: A Method for Linking Preschool Physical Activity and Outdoor Design." Medicine \& Science in Sports \& Exercise 42: 513-519.

Dowda, M., R. R. Pate, S. G. Trost, M. J. C. A. Almeida, and J. R. Sirard. 2004. "Influences of Preschool Policies and Practices on Children's Physical Activity." Journal of Community Health 29: 183-196.

European Commission's Expert Group on Gender and Employment Issues (EGGE). 2009. The Provision of Childcare Services. A Comparative Review of 30 European Countries. Luxemburg: Office for Official Publications of the European Communities. 
Finn, K. J., N. Johannsen, and B. Specker. 2002. "Factors Associated with Physical Activity in Preschool Children." The Journal of Pediatrics 140: 81-85.

Gubbels, J. S., S. P. J. Kremers, D. H. H. Van Kann, A. Stafleu, M. J. J. M. Candel, P. C. Dagnelie, C. Thijs, and N. K. de Vries. 2011. "Interaction Between Physical Environment, Social Environment, and Child Characteristics in Determining Physical Activity at Child Care." Health Psychology 30: 84-90.

Gubbels, J. S., D. H. H. Van Kann, and M. W. J. Jansen. 2012. "Play Equipment, Physical Activity Opportunities, and Children's Activity Levels at Childcare." Journal of Environmental and Public Health. doi:10.1155/2012/326520.

Hannon, J. C., and B. B. Brown. 2008. 'Increasing Preschoolers' Physical Activity Intensities: An Activity-friendly Preschool Playground Intervention." Preventive Medicine 46: 532536.

Hinkley, T., D. Crawford, J. Salmon, A. D. Okely, and K. Hesketh. 2008. "Preschool Children and Physical Activity." American Journal of Preventive Medicine 34: 435-441.

OECD. 2014. OECD Family Database. Paris: OECD. Last updated May 2014. Retrieved June 1, 2014 from http://www.oecd.org/els/family/PF3_2_Enrolment_in_childcare_and_ preschools_1May2014.pdf.

Oliver, M., G. M. Schofield, and G. S. Kolt. 2007. "Physical Activity in Preschoolers. Understanding Prevalence and Measurement Issues." Sports Medicine 37: 1045-1070.

Pate, R. R., K. McIver, M. Dowda, W. H. Brown, and C. Addy. 2008. "Directly Observed Physical Activity Levels in Preschool Children." Journal of School Health 78: 438-444.

Pate, R. R., J. R. O’Neill, and J. Mitchell. 2010. "Measurement of Physical Activity in Preschool Children." Medicine \& Science in Sports \& Exercise 42: 508-512.

Pate, R. R., K. A. Pfeiffer, S. G. Trost, P. Ziegler, and M. Dowda. 2004. "Physical Activity among Children Attending Preschools." Pediatrics 114: 1258-1263.

Recommendations for Physical Activity in Early Childhood Education. 2005. "Handbooks of the Ministry of Social Affairs and Health 2005:17." Retrieved February 3, 2012, from http://www.stm.fi/c/document_library/get_file?folderId=28707\&name=DLFE-3739. pdf\&title=Varhaiskasvatuksen_liikunnan_suositukset_fi.pdf.

Reilly, J. J. 2010. "Low Levels of Objectively Measured Physical Activity in Preschoolers in Child Care." Medicine \& Science in Sports \& Exercise 42: 502-507.

Ridgers, N. D., G. Stratton, S. J. Fairclough, and W. R. Twisk. 2007. "Long-term Effects of a Playground Markings and Physical Structures on Children's Recess Physical Activity Levels." Preventive Medicine 44: 393-397.

Strong, W. B., R. M. Malina, C. R. Blimkie, S. R. Daniels, R. K. Dishman, and B. Gutin. 2005. "Evidence Based Physical Activity for School-age Youth." Journal of Pediatrics 146: 732 737.

Trost, S. G. 2007. "State of the Art Reviews: Measurement of Physical Activity in Children and Adolescents." American Journal of Lifestyle Medicine 1: 299-314.

Verbestel, V., E. Van Cauwenberghe, V. De Coen, L. Maes, I. De Bourdeaudhuij, and G. Cardon. 2011. "Within- and Between-day Variability of Objectively Measured Physical Activity in Pre-schoolers." Pediatric Exercise Science 23: 366-378.

Ward, D. S. 2010. "Physical Activity in Young Children: The Role of Child Care." Medicine \& Science in Sports \& Exercise 42: 499-501.

Zask, A., E. van Beurden, L. Barnett, L. O. Brooks, and U. C. Dietrich. 2001. "Active School Playgrounds-myth or Reality? Results of the 'Move it Groove it' Project." Preventive Medicine 33: 402-408. 